\title{
Variance component estimation of female fertility traits in two indigenous and two European beef cattle breeds of South Africa
}

\author{
T. Rust ${ }^{1 \#}$ and E. Groeneveld ${ }^{2}$ \\ ${ }^{1}$ ARC Animal Improvement Institute, Irene 0062, South Africa \\ ${ }^{2}$ Institute of Animal Husbandry and Animal Behaviour, Federal Agricultural Research Centre, 31535, Mariensee, \\ Germany
}

\begin{abstract}
Field data for the period 1976 to 1998 from South African and Namibian Afrikaner, Drakensberger, SA Angus and Simmentaler beef cattle breeds was used to investigate two fertility traits, calving rate (CR) and calving success (CS). Calving rate, a lifetime reproduction trait of the dam, was defined as number of calves produced by the dam divided by the age of the dam in years. For CS, a score of one was allocated for successful calvings and zero for failure to calve. All variances were estimated using REML procedures. The heritability estimate for CR was low (0.04) and that for CS was zero for all four breeds. After analysing CS using GFCAT (sire model) a heritability of 0.27 was estimated for the Afrikaner, suggesting that additive genetic variance does exist for CS in southern African beef cattle populations.
\end{abstract}

Keywords: beef cattle, fertility traits, GFCAT, heritabilities, REML, variance component estimation

\# Corresponding author. e-mail: tina@irene.agric.za

\section{Introduction}

In current national genetic evaluations in Southern Africa, estimated breeding values (EBVs) for growth traits are reported without any indication of the reproductive ability of the animals. This void could lead to the assumption that differences between animals in genetic merit for reproduction and fitness traits are trivial. However, no records exist of reproductive abilities except those that can be deducted from birth dates. It is difficult to identify economically important traits relating to reproduction that can be used in routine evaluations. A number of traits have been identified and investigated in the literature. Improvement of cow fertility in beef cattle is considered to be limited because of low heritabilities for cow reproductive traits (Davenport et al., 1965; Dearborn et al., 1973). Some studies from subtropical environments have, however, reported moderate heritabilities (Deese \& Koger, 1967; Seebeck, 1973; Cruz et al., 1978; Thorpe et al., 1981; Turner, 1982; Meyer et al., 1990; Rust \& Kanfer, 1998). The EBVs for fertility traits are difficult to estimate partly because the expression of the reproductive potential of animals is often constrained by the management systems farmers employ (Notter \& Johnson, 1988; Meyer et al., 1990; Notter, 1995). When managerial and nutritional conditions are optimal, most animals will reproduce, but in conditions that are less favourable, only those with the highest genetic merit for reproductive fitness will reproduce (Morris, 1980; Notter, 1995).

Traits considered in the literature to describe female fertility usually include breeding dates or dates of joining. The information on these breeding and joining dates is unfortunately not available from the South African Performance Testing Scheme. The only information available is calving date. However, calving date is not suitable for use in the South African National Beef Cattle Improvement Scheme (NBCIS) because the starting date as well as duration of joining within the same breed differs between breeders in different climatic regions. The purpose of this study was to determine means to express the genetic reproductive merit of animals for possible use in a Southern African National analysis.

\section{Materials and Methods}

Field data was obtained from the Integrated Registration and Genetic Information System (INTERGIS) of South Africa for purebred Afrikaner, Drakensberger, SA Angus and Simmentaler beef cattle breeds for the period 1976 to 1998 . The data was edited to eliminate animals with unknown birth dates. Dams born before 1973 were eliminated from the data since the integrity of the earlier data could not be verified. All the calves of embryo donor cows were omitted as well as all animals of contemporary groups with less than 10 animals. 
Due to the fact that no measurements concerning fertility other than calvings were available, the choices were fairly limited. The first trait investigated was calving rate (CR), a lifetime reproduction trait that was similar to a trait defined by Meyer et al. (1990). Given the information available, CR was defined as the number of calves born to a cow divided by the cow's age. The cow's herd entry and exit date information are not recorded in the NBCIS, and as a substitute, the entry date was replaced by the birth date of the cow while it's exit date was replaced by the cow's last available calving date.

A second trait, calving success (CS), was defined as a binary trait. It is considered to be a yearly measurement. Thus, a CS of 1 was assigned if the cow calved and a score of 0 , if not. Southern African farmers, especially those of some of the indigenous breeds, do not breed heifers before the age of three years. Therefore, two approaches were used to determine the starting year for CS:

1. For the two indigenous breeds (Afrikaner and Drakensberger) it was expected of all heifers to calve for the first time at the age of three. If she failed, a CS of zero was assigned in her third year.

2. For the European breeds (SA Angus and Simmentaler) it was expected of all heifers to calve for the first time at the age of two. If she failed, a CS of zero was assigned in her second year.

Any cow calving before her first expected calving date was credited for this performance and her record started at the year of first calving.

Characteristics of the data structure with the phenotypic means and standard deviations are summarized in Table 1.

Table 1 General statistics of the data

\begin{tabular}{llcccc}
\hline \multirow{2}{*}{ Trait } & \multicolumn{1}{c}{ Breed } & $\begin{array}{c}\text { Number of } \\
\text { Records }\end{array}$ & $\begin{array}{c}\text { Number of } \\
\text { Pedigree }\end{array}$ & Average & s.d. \\
\hline \multirow{2}{*}{ CR } & Afrikaner & 34566 & 46570 & 0.441 & 0.153 \\
& Afrikaner - Selected data & 927 & 2803 & 0.551 & 0.150 \\
\hline \multirow{4}{*}{$\mathrm{CS}$} & Afrikaner & 209420 & 50028 & 0.608 & 0.488 \\
& Afrikaner - Selected data & 3922 & 192 & 0.744 & 0.418 \\
& Drakensberger & 132165 & 31164 & 0.699 & 0.459 \\
& SA Angus & 89752 & 21680 & 0.716 & 0.451 \\
& Simmentaler & 250000 & 62197 & 0.751 & 0.432 \\
\hline
\end{tabular}

$\mathrm{CR}$ - calving rate

$\mathrm{CS}$ - calving success

To test whether results obtained from the complete data sets for CR and CS were not a symptom of the data structure, a selected data set on one of the four breeds, the Afrikaner, was constructed from proven sires. Requirements for this selected data set were that all sires selected had to be used in more than four herds and sired more than 75 offspring. Each herd*year level had to represent more than nine dams with measurements resulting in a selected data set of 3922 measurements. The general statistics of the selected Afrikaner data are given in Table 1.

The REML VCE4 package (Groeneveld, 1994a,b; Groeneveld et al., 1996; Groeneveld \& GarcíaCortés, 1998) was used to estimate the variance components utilising analytical gradients (Neumaier \& Groeneveld, 1998).

For variance component estimation of CS, a repeatability model was used. Although an animal model is not the optimal model to use for analysis of categorical data, the authors hoped to detect some variance that could be used to predict breeding ability. Matos et al. (1997) concluded that the goodness of fit of linear and non-linear models for discrete traits was similar, and with respect to prediction ability, differences between linear and non-linear mixed models were negligible.

Two models were fitted for both traits, herd*year interactions were treated as either fixed or random. For CR, two herd-year effects were included in the model, the first being the herd and year the dam was born in (DHerd*year) and the second, the herd and year of her last calf (CHerd*year). For CS, the age of the dam in years was included as a fixed effect in all the models. In matrix notation the model for both traits and all breeds was: 
Where: $\mathbf{y}=$ vector of observations

$$
\begin{array}{ll}
\mathbf{X}, \mathbf{Z}_{\mathbf{u}}= & \text { incidence matrix for all fixed and genetic effects, respectively } \\
\beta, \mathbf{u}= & \text { vector of unknown parameters for fixed and animal effects, respectively } \\
\mathbf{e} & =\text { vector of residuals }
\end{array}
$$

On the selected data set of the Afrikaner sires, for CS only, a sire model was performed to substantiate the results from the animal model analysis:

Where: $\mathbf{y}=$ vector of observations

$\mathbf{X}, \mathbf{Z}=\quad$ incidence matrix for all fixed and genetic effects, respectively

$\beta, \mathbf{u}=\quad$ vector of unknown parameters for fixed and sire effects, respectively

e $\quad=$ vector of residuals

Threshold models assume the existence of an underlying, unobservable normal variable that is categorized through fixed thresholds. A trait such as CS is phenotypically expressed in only two categories even though diverse combinations of genetic as well as environmental influences determine the phenotype. To determine the heritability for CS on the underlying scale, a GFCAT (Konstantinov, 1992) sire model analysis was performed on the selected Afrikaner data set. The location parameters $(\mu)$ were modeled as:

$$
=\mathbf{X} \beta+\mathbf{Z u}
$$

Where: $\quad \mathbf{X}, \mathbf{Z}=\quad$ incidence matrix for all fixed and genetic effects, respectively

$\beta, \mathbf{u}=\quad$ vector of unknown parameters for fixed and sire effects, respectively

\section{Results}

\begin{tabular}{|c|c|c|c|c|c|c|c|c|}
\hline & $\mathrm{Y}$ & \multirow[t]{2}{*}{ Model } & \multirow[t]{2}{*}{ Factor } & \multirow[t]{2}{*}{ Type } & \multicolumn{4}{|c|}{ Number of levels } \\
\hline & & & & & Afrikaner & Dr'berger & SA Angus & Simmentaler \\
\hline & \multirow{6}{*}{$\mathrm{CR}$} & & Dherd*year & $\mathrm{F} / \mathrm{R}$ & 3088 & & & \\
\hline & & $\mathrm{AM}$ & Cherd*year & $\mathrm{F} / \mathrm{R}$ & 3483 & & & \\
\hline & & & Animal & A & 46570 & & & \\
\hline & & $\mathrm{AM}$ & Dherd*year & $\mathrm{F} / \mathrm{R}$ & 86 & & & \\
\hline & & Selected & Cherd*year & $\mathrm{F} / \mathrm{R}$ & 109 & & & \\
\hline & & Data Set & Sire & A & 2803 & & & \\
\hline \multirow{6}{*}{\multicolumn{2}{|c|}{$\mathrm{CS}$}} & & Herd*year & $\mathrm{R} / \mathrm{F}$ & 4960 & 2479 & 1930 & 6328 \\
\hline & & $\mathrm{AM}$ & Dam age & $\mathrm{F}$ & 19 & 19 & 19 & \\
\hline & & & Animal & A & 50028 & 31164 & 21680 & 62197 \\
\hline & & SM & Herd*year & $\mathrm{F} / \mathrm{R}$ & 261 & & & \\
\hline & & Selected & Dam age & $\mathrm{F}$ & & & & \\
\hline & & Data set & Sire & $\mathrm{S}$ & 192 & & & \\
\hline \multicolumn{9}{|c|}{ AM - Animal Model } \\
\hline SM & - & Model & & & & & & \\
\hline $\mathrm{F}$ & - & & & & & & & \\
\hline $\mathrm{R}$ & - & dom & & & & & & \\
\hline A & - & imal & & & & & & \\
\hline $\mathrm{S}$ & - & & & & & & & \\
\hline
\end{tabular}

The final REML model for CR is presented in Table 2, resulting in approximately 53141 Mixed Model Equations for the complete Afrikaner data set and 2998 equations for the selected Afrikaner data set.

Table 2 The final statistical models used for calving rate (CR) and calving success (CS)

The estimates and corresponding derived ratios for $\mathrm{CR}$ are presented in Table 3 for the models including the Dherd*year and Cherd*year effects as fixed and random. The analysis for CR on the selected Afrikaner data using the linear animal model resulted in similar results to those from the complete Afrikaner data set, indicating that the results obtained from the complete data sets for all breeds were probably not due to bad data structure. 
Table 3 Variances and corresponding ratios for calving rates (CR) from Afrikaner beef cattle

\begin{tabular}{|c|c|c|c|c|c|c|c|c|c|c|c|c|c|c|c|}
\hline \multirow{2}{*}{$\begin{array}{l}\text { Mo- } \\
\text { del }\end{array}$} & \multirow{2}{*}{ Data } & \multirow{2}{*}{$\begin{array}{l}\text { Fixed/ } \\
\text { Random }\end{array}$} & \multicolumn{4}{|c|}{ Variances } & \multicolumn{4}{|c|}{ Ratios } & \multirow{2}{*}{$\begin{array}{l}\text { St } \\
\text { at } \\
\text { us }\end{array}$} & \multicolumn{4}{|c|}{ Standard errors } \\
\hline & & & $\sigma_{\mathrm{e}}^{2}$ & $\sigma_{\mathrm{a}}^{2}$ & $\sigma_{\text {Dhy }}^{2}$ & $\sigma_{\text {Chy }}^{2}$ & E & $\mathrm{h}^{2}$ & Dhy & Chy & & e & $\mathrm{a}$ & Dhy & Chy \\
\hline \multirow{4}{*}{$\mathrm{AM}$} & \multirow{2}{*}{$\begin{array}{c}\text { Total } \\
\text { Data set }\end{array}$} & $\mathrm{F}$ & 0.01 & 0.00 & & & 0.96 & 0.04 & & & 1 & 0.01 & 0.00 & & \\
\hline & & $\mathrm{R}$ & 0.01 & 0.00 & 0.01 & 0.01 & 0.31 & 0.03 & 0.29 & 0.37 & 1 & 0.00 & 0.00 & 0.00 & 0.00 \\
\hline & \multirow{2}{*}{$\begin{array}{l}\text { Selected } \\
\text { Data set }\end{array}$} & $\mathrm{F}$ & 0.01 & 0.00 & & & 0.94 & 0.06 & & & 1 & 0.07 & 0.07 & & \\
\hline & & $\mathrm{R}$ & 0.01 & 0.00 & 0.01 & 0.01 & 0.36 & 0.02 & 0.26 & 0.36 & 1 & 0.03 & 0.03 & 0.03 & 0.03 \\
\hline \multicolumn{16}{|c|}{ AM - Animal Model } \\
\hline $\mathrm{F}$ & Fixed & & & & & & & & & & & & & & \\
\hline
\end{tabular}

For CS, the final REML models for all four breeds are given in Table 2, resulting in approximately 55 000, 34 000, 24000 and 69000 Mixed Model Equations for the Afrikaner, Drakensberger, SA Angus and Simmentaler, respectively. The estimates and corresponding derived ratios for CS are presented in Table 4 for the models including the herd*year effect as fixed and random. The status at the end of the optimization is given. When optimization did not finish with status 1, no standard errors are given.

Table 4 Variances and corresponding ratios for calving success (CS) with herd-year included as a random effect in the model. The status at optimization is indicated

\begin{tabular}{|c|c|c|c|c|c|c|c|c|c|c|c|c|}
\hline \multirow{2}{*}{$\begin{array}{l}\text { Mo- } \\
\text { del }\end{array}$} & \multirow[t]{2}{*}{ Breed } & \multirow{2}{*}{$\begin{array}{c}\text { Fixed/ } \\
\text { Random }\end{array}$} & \multicolumn{3}{|c|}{ Variances } & \multicolumn{3}{|c|}{ Ratios } & \multirow{2}{*}{$\begin{array}{l}\text { Sta } \\
\text { tus }\end{array}$} & \multicolumn{3}{|c|}{ Standard errors } \\
\hline & & & $\sigma_{\mathrm{e}}^{2}$ & $\sigma_{\mathrm{a}}^{2}$ & $\sigma_{\text {hy }}^{2}$ & $\mathrm{e}$ & $h^{2}$ & hy & & $\mathrm{e}$ & $\mathrm{a}$ & hy \\
\hline \multirow[t]{4}{*}{ AM } & Afrikaner & & 0.17 & 0.00 & & 1.00 & 0.00 & & 2 & & & \\
\hline & Drakensberger & $\mathrm{F}$ & 0.13 & 0.00 & & 0.99 & 0.02 & & 1 & 0.00 & 0.00 & \\
\hline & SA Angus & & 0.13 & 0.00 & & 1.00 & 0.00 & & 1 & 0.00 & 0.00 & \\
\hline & Simmentaler & & 0.14 & 0.00 & & 1.00 & 0.00 & & 1 & 0.00 & 0.00 & \\
\hline SM & Afrikaner & $\mathrm{F}$ & 0.14 & 0.00 & & 1.00 & 0.00 & & 1 & 0.00 & 0.00 & \\
\hline \multirow[t]{4}{*}{$\mathrm{AM}$} & Afrikaner & & 0.17 & 0.00 & 0.08 & 0.67 & 0.00 & 0.33 & 2 & & & \\
\hline & Drakensberger & & 0.13 & 0.00 & 0.10 & 0.57 & 0.01 & 0.43 & 1 & 0.01 & 0.00 & 0.01 \\
\hline & SA Angus & $\mathrm{R}$ & 0.13 & 0.00 & 0.04 & 0.75 & 0.00 & 0.25 & 1 & 0.01 & 0.00 & 0.01 \\
\hline & Simmentaler & & 0.14 & 0.00 & 0.05 & 0.74 & 0.00 & 0.26 & 1 & 0.00 & 0.00 & 0.00 \\
\hline SM & Afrikaner & $\mathrm{R}$ & 0.14 & 0.00 & 0.05 & 0.76 & 0.00 & 0.24 & 1 & 0.02 & 0.00 & 0.02 \\
\hline \multicolumn{13}{|c|}{ AM - Animal Model } \\
\hline SM - & Sire Model & & & & & & & & & & & \\
\hline- & Fixed & & & & & & & & & & & \\
\hline $\mathrm{R}$ & Random & & & & & & & & & & & \\
\hline
\end{tabular}

The analysis for CS on the selected Afrikaner data using the linear sire model resulted in similar results to those from the complete Afrikaner data set using the linear animal model. Results from the linear sire model analysis of CS are presented in Table 4.

Using GFCAT sire model for analysing the selected Afrikaner data set proved that genetic variation did exist for CS on the underlying scale. The $\sigma^{2}{ }_{e} / \sigma_{s}^{2}$ ratio was estimated as equal to 13.736 with the corresponding $\sigma_{\mathrm{s}}^{2}=0.0728$ and $\mathrm{h}^{2}=0.27$, indicating a moderate to high heritability on the underlying scale.

\section{Discussion}

While CR comes close to the overall breeding objective "overall reproductive performance" (ORP), it does have serious deficiencies. The first problem lies in the lack of information pertaining to the cow's herd entry and exit dates. As a substitute, the entry date was replaced by the birth date of the cow while its exit date was replaced by the cow's last available calving date. The effect of this was to exclude variation (also genetic variation if it exists) from this trait, because all animals finished with a calving. Cows that did not conceive or did not produce another calf, although they remained in the herd for perhaps another year, received the same trait measurements as cows that were culled right after calving. Thus, CR, as defined, captured a reduced amount of total variation in reproductive performance. How this affected the heritability 
is not clear. It could be argued that much of the culling is due to reproductive failure and by omitting information that contributed to an additive genetic component, resulted in an underestimate of the true additive heritability.

Replacing the true entry date of a cow into the herd with it's birth date possibly had a similar effect. It increased the overall variation, including differences in managerial policies, resulting in genetic components estimated on the basis of CR as defined, to be an underestimate. Being a lifetime statistic, CR is made up from a varying number of calvings depending on the parity of the cows with the result that the accuracy of $\mathrm{CR}$ on the basis of different parities is different. To model this effect correctly, different residual variances should be used, depending on the number of calves included in each CR. While this could be done rather easily for the components of BLUP, the authors did not see a way to include this into REML variance component estimation on the basis of analytical gradients, which was the procedure that was used. Another problem related to a lifetime statistic, is the inability to adequately adjust for environmental effects. A cow with eight calves might have produced them over a number of years under very different environmental conditions. Since the cow's CR is based on all eight calvings it is not possible to adjust for each individual calving. The effect of this would be an inflation of the residual variance, which in turn would lower the heritability. In conclusion, $\mathrm{CR}$ as was defined, does have severe limitations and most probably underestimated the true additive genetic variation for a properly defined CR. Thus, the estimates obtained, should be considered as the lower bounds of the true estimates. In attempting to overcome some of the difficulties experienced with CR, CS was defined and investigated. However, some serious constraints existed for this trait as well, since no information was available on cows that did not calve. Zero values were thus allocated if no calf was recorded during a year. Non-calving migrates were allocated to the next herd. The problems caused by not knowing the exit date of a cow have already been outlined above. For CS, the last record for each cow is always success, which clearly does not reflect reality. Thus, the true CS estimate would be lower. The way CS was defined, resulted in repeated records for each cow. Compared to CR, the accuracy will increase, as different numbers of calves per cow will automatically be adjusted for in the repeatability model. Furthermore, each calving can now be adjusted to the pertaining environmental effects. Thus, CS will have better properties than CR. However, CS is a binary trait, which certainly violates the BLUP model assumptions.

From the analysis done on all four breeds it seems as if no additive genetic variation exists for CS. It can be concluded that no additive genetic variance exists for CS in Southern African beef breeds, but other possible reasons for these results should also be considered: Firstly, it could be that the non-genetic effects included in the model did not describe the data well and resulted in an inability of linear mixed models to properly split the genetic components. Secondly, further investigation is needed into the methodology used to analyse the data. In the study done by Meijering \& Gianola (1985), they compared ranking properties of linear (BLUP) and non-linear (GFCAT) methods of sire evaluation for dichotomous or ordered categorical responses. The endpoint measured was the Monte Carlo realised response to truncation selection upon predicted sire values. They concluded that when a mixed model was required to describe variation of binary responses, GFCAT performed significantly better than BLUP when heritability in the conceptual underlying scale was moderate to high. Contrary to this, Matos et al. (1997) concluded that the goodness of fit of linear and non-linear models for discrete reproduction traits was similar, and with respect to prediction ability, differences between linear and non-linear mixed models were negligible. Unfortunately, no variation for CS could be detected by REML in this study, making it impossible to compare results between the two methods used to analyse CS. Using a GFCAT sire model on the selected Afrikaner data set, a heritability of $27 \%$ was estimated, indicating that variance for CS does exist on the underlying scale.

\section{Recommendations}

Presently, not one of the two traits investigated, namely CR and CS, seems to be options for expressing the reproductive merit of animals in a Southern African analysis using either REML or GFCAT mixed model methodology. The heritability of CR is low (0.04), resulting in slow genetic improvement over many years. Furthermore, there are no methodologies available at present to accommodate data where the residual variance of each observation differs. Since the data was not recorded for the purpose of describing reproduction performance there are too many difficulties and assumptions made when analysing CS. However, a GFCAT sire model can be a consideration, but because of the outlined problems with the data, caution must be taken when estimating breeding values for sires.

The following recommendations to the South African recording schemes are made: 
1. All entry and exit dates of heifers and cows should be recorded.

2. The pregnancy status of the animals on entering and exiting a herd should be known.

3. All joining dates should be recorded, and if no calf results from this joining, it must be recorded.

Even though it is not currently possible to do a national genetic analysis for reproduction traits due to the shortcomings of the recording scheme as outlined in the discussion, further investigation on appropriate sources of data such as experimental herds, should continue. This will ensure that, if the recommendations of this study are followed, the know-how and methodology will be available to do a national genetic evaluation as soon as enough data has been collected.

\section{References}

Cruz, V., Kroger, M. \& Warnick, C., 1978. Heritability estimates of reproductive efficiency in Brahman beef cattle. $4^{\text {th }}$ World Conf. Anim. Prod. Buenos Aires, August 1978, pp. 605.

Davenport, R.L., Stonaker, H.L., Riddle, K. \& Sutherland, T.M., 1965. Heritability of reproductive performance in inbred and linecross beef cows. J. Anim. Sci. 24, 434-437.

Dearborn, D.D., Koch, R.M., Cundiff, L.V., Gregory, K.E. \& Dickerson, G.E., 1973. An analysis of reproductive traits in beef cattle. J. Anim. Sci. 36, 1032-1040.

Deese, R.E. \& Koger, M., 1967. Heritability estimates of fertility in Brahman and crossbred cattle. J. Anim. Sci. 26, 984-987.

Groeneveld, E., 1994a. REML VCE - a multivariate, multi-model restricted maximum likelihood (co)variance component estimation package. In: Proceedings of an EC Symposium on Application of Mixed Linear Models in the Prediction of Genetic Merit in Pigs.

Groeneveld, E., 1994b. VCE - a multivariate, multi-model REML (co)variance component estimation package. In $5^{\text {th }}$ World Congress on Genetic Applied to Livestock Production, Guelph, Canada 22, 4748.

Groeneveld, E., Gsató, L., Farkas, J. \& Randóczi, L., 1996. Multivariate Genetic Evaluation in the Hungarian Large White and Landrace Populations. Arch. Anim. Breed 39, 513-531.

Groeneveld, E. \& García-Cortés, A., 1998. VCE4.0, a (co) variance component packages for frequentist and Bayesians. In: $6^{\text {th }}$ World Congress on Genetics Applied to Livestock Production, Armidale, Australia 27, 455-458.

Konstantinov, K.V., 1992. GFCAT is a set of programs for analysis of mixed threshold models with support from REML-TYPE variance components estimation. University of the Orange Free State, P.O. Box 339, Bloemfontein, 9300, RSA.

Matos, C.P.A., Thomas, D.L., Gianola, D., Perez-Enciso, M. \& Young, L.D., 1997. Genetic analysis of discrete reproductive traits in sheep using linear and non-linear model: II. Goodness of fit and predictive ability. J. Anim. Sci. 75, 88-94.

Meijering, A. \& Gianola, D., 1985. Linear versus non-linear methods of sire evaluation for categorical traits: a simulation. Gen. Sel. Evol. 17, 115-132.

Meyer, K., Hammond, K., Parnell, P.F., Mackinnon, M.J. \& Sivarajasingam, S., 1990. Estimates of heritability and repeatability for reproductive traits in Australian beef cattle. Livest. Prod. Sci. 24, 1530.

Morris, C.A., 1980. A review of relationships between aspects of reproduction in beef heifers and their lifetime reproduction. 2. Associations with relative calving date and with dystocia. Anim. Breed. Abstr. 48, 753-767.

Neumaier, A. \& Groeneveld, E., 1998. Restricted maximum likelihood estimation of (co) variances in sparse linear models. Genet. Sel. Evol. 30, 3-26.

Notter, D.R., 1988. Evaluating and reporting reproductive traits. Proc. Beef Improvement Fed. Res. Symp. Annual meeting, Albuquerque, NM, May 12-14, 21-42.

Notter, D.R. \& Johnson, M.H., 1988. Simulation of genetic control of reproduction in beef cows. IV. Withinherd breeding value estimation with pasture mating. J. Anim. Sci. 66, 280-286.

Notter, D.R., 1995. Genetic improvement of fertility using correlated traits and molecular markers. Proc. $11^{\text {th }}$ Congress Brussileiro de Reprodução Animal, Belo Horizonte, MG, Brazil. July 10-14, 121-130.

Rust, T. \& Kanfer. F.H.J., 1998. Variance component and breeding value estimation for age at first calving of Afrikaner and Drakensberger beef cattle. Proc. $36^{\text {th }}$ Nat. Congr. S. Afr. Soc. Anim. Sci., Stellenbosch, South Africa. p. 85. 
Seebeck, R.M., 1973. Sources of variation in the fertility of a herd of Zebu, British and Zebu x British cattle in Northern Australia. J. Agric. Sci., Camb. 81, 253-266.

Thorpe, W., Cruickshank, D.K. \& Thompson, R., 1981. Genetic and environmental influences on beef cattle production in Zambia. 4. Weaner production from purebred and reciprocal crossbred dams. Anim. Prod. 33, 165-177.

Turner, H.G., 1982. Genetic variation of rectal temperature in cows and its relationship to fertility. Anim. Prod. 35, 401-412. 